\title{
Effect of Deformation Conditions on Mechanical Properties of Zr-based Metallic Glasses
}

\author{
Zhenxiang $\mathrm{ZHAO}^{2}$, Chunyan $\mathrm{LI}^{1,2^{*}}$, Fuping $\mathrm{ZHU}^{2}$, Xinling $\mathrm{LI}^{2}$, Shengzhong $\mathrm{KOU}^{1,2}$
}

1 State Key Laboratory of Advanced Processing and Reuse of Nonferrous Metals, Lanzhou University of Technology, Lanzhou Gansu 730050

2 School of Materials Science and Engineering, Lanzhou University of Technology, Lanzhou Gansu 730050

*Corresponding Author: Chunyan LI, Lanzhou University of Technology, Lanzhou Gansu; email address licywz@163.com

\begin{abstract}
:
In this paper, the effects of different strain rate $\left(1 \times 10^{-5} \mathrm{~s}^{-1}, 5 \times 10^{-5} \mathrm{~s}^{-1}, 1 \times 10^{-4} \mathrm{~s}^{-1}, 5 \times 10^{-4} \mathrm{~s}^{-1}, 1 \times 10^{-3} \mathrm{~s}^{-1}\right)$ and aspect ratio $(1: 1,1.5: 1,2: 1,2.5: 1$, 3:1) on mechanical properties of $\mathrm{Zr}$-based metallic glasses at room temperature were investigated. The results indicate that as the strain rate increases, the plastic strain and compressive strength of the specimens gradually decrease. The specimen with the strain rate of $1 \times 10^{-5} \mathrm{~s}^{-1}$ exhibits the higher plastic strain of $10.25 \%$, compressive strength of $2002 \mathrm{MPa}$ and fracture strength of $1999 \mathrm{MPa}$. In addition, accompanied with the increase in aspect ratio, the plastic strain of the specimens declines from $25.42 \%$ to $1.97 \%$, meanwhile, the compressive strength and fracture strength of the specimens also present declining trend.
\end{abstract}

Keywords: Zr-based Metallic glasses; mechanical properties; plastic strain; strain rate; aspect ratio

\section{Introduction}

Metallic glass is a novel type of metal material with longrange disorder, short-range or medium-range ordered structure $^{[1]}$. Metallic glasses are produced by the rapid solidification from liquid metals, which inhibit the crystallization process. Compared to traditional crystalline materials, metallic glasses hold a variety of unique advantages because of their special atomic structure, such as higher strength, higher hardness, higher elastic strain, and elastic limit, lower elastic modulus ${ }^{[2-5]}$, and good magnetism ${ }^{[6]}$. However, metallic glass, a thermodynamic metastable atomic structure, can cause crystallization when the temperature and pressure reach a certain condition ${ }^{[1,7]}$. At the same time, since there are no microstructure defects such as grain boundary and dislocation, the plastic deformation at room temperature is concentrated in the highly localized shear band, which can easily lead to adiabatic shear and non-uniform flow of materials. The non-uniform flow of materials further gives rise to brittle fracture metallic glasses, which is also one of the bottlenecks restricting the application of metallic glasses as engineering structural materials ${ }^{[8]}$. The second phase plastic particles were first applied to metallic glasses by researchers, thus improving the plastic deformation of bulk metallic glasses at room temperature to a certain extent ${ }^{[9]}$. Zhang $S \mathrm{G}$ et $\mathrm{al}^{[10]}$. studied the unidirectional compression deformation behavior of $\mathrm{Zr}_{41.2} \mathrm{Ti}_{13.8} \mathrm{Cu}_{12.5} \mathrm{Ni}_{10} \mathrm{Be}_{22.5}$ amorphous alloy under different strain rates in the temperature range of supercooled liquid region, and found that the flow stress was only $74 \mathrm{MPa}$ at $2 \times 10^{-2} \mathrm{~s}^{-1}$, which was more suitable for superplastic processing. Chen D M et all ${ }^{[11]}$ studied the change of mechanical properties of $\mathrm{Zr}_{41.2} \mathrm{Ti}_{13.8} \mathrm{Cu}_{12.5} \mathrm{Ni}_{10} \mathrm{Be}_{22.5}$ bulk amorphous alloy composite under different strain rates, which found that the plasticity of this kind of amorphous alloy composite increased greatly under quasistatic compression. Lewandowski ${ }^{[12]}$ pointed out that hydrostatic pressure has a certain influence on the plastic deformation of Zr-based Metallic glasses, and its plastic deformation ability can be more than $10 \%$ under limited conditions. Yuan $\mathrm{B}^{[13]}$. Studied the relationship between strain rate and serrated flow behavior of amorphous alloy, and pointed out that the number of standard serrations was linear with strain rate. With the decrease of strain rate, the number of standard serrations increases gradually. There is a strain rate correlation in plastic deformation at room temperature on account of the uneven deformation of metallic glasses. It is found that increasing of crystal phase content in metallic glass led to an increase in the strain rate sensitivity of metallic glass ${ }^{[14]}$. In addition, the fracture strength of metallic glass also demonstrate decreasing trend as the compression strain rate of metallic glass increases ${ }^{[15]}$ 
Zr-based Metallic glasses characterized by high strength, high elasticity, superplastic, high hardness, high wear resistance and high corrosion resistance, generates a broad application prospect ${ }^{[16]}$. Moreover, Zr-based Metallic glasses has good dynamic compression properties, positive strain rate effect, good extensibility, excellent inherent low frequency vibration damping performance ${ }^{[17]}$, excellent electrocatalytic activity ${ }^{[18]}$, and good magnetic properties after adding iron ${ }^{[19]}$. High hardness and fairly low elastic modulus make Zr-based Metallic glasses a candidate material for bioimplant ${ }^{[20]}$. Based on the understanding of the mechanism of nanocrystalline reinforced $\mathrm{Zr}$-based Metallic glasses, Zr-based metallic glasses have been widely used in structural materials ${ }^{[21]}$.

In this paper, the effects of different compression strain rate and aspect ratio on the mechanical properties of $\mathrm{Zr}$-based metallic glasses at room temperature were explored. The compression deformation behavior of metallic glasses was investigated by analyzing the stressstrain curve, fracture microstructure and shear band evolution characteristics.

\section{Experimental materials and methods}

Master alloy with nominal composition of $\mathrm{Zr}_{61.88} \mathrm{Cu}_{18} \mathrm{Ni}_{10.12} \mathrm{Al}_{10}$ was chosen for this experiment, the experimental materials were high-purity zirconium ( $\mathrm{Zr}$ 99.95\%), copper ( $\mathrm{Cu} 99.98 \%)$, aluminum ( $\mathrm{Al} 99.98 \%)$ and nickel (Ni 99.98\%). The master alloy ingots were prepared by magnetic suspension smelting process in highly pure argon atmosphere. The melting process of the master alloy needs to be repeated four times to ensure the uniform distribution of the chemical elements in the parent alloy. The alloy bars with diameters of $3 \mathrm{~mm}$ were fabricated by copper model suction casting method under argon atmosphere. The metal bars were cut by a diamond slicer to obtain the compression specimen with different aspect ratio of 1:1, 1.5:1, 2:1, 2.5:1 and 3:1. In order to eliminate the interference of other factors other than deformation conditions, compression specimens with the same amorphous rod were used for three repeated experiments. The specimen structure of was identified by X-ray diffraction (XRD, Cu Ka radiation). The diffraction angle range 2-theta is between $20^{\circ}$ and $80^{\circ}$, and the step length of scanning is $0.02^{\circ}$. The glass transition and crystallization behavior of the specimens were evaluated by an STA449 thermal differential calorimeter (DSC) under the protection of argon with a heating rate of $20 \mathrm{~K} \mathrm{~min}^{-1}$. The heating temperature range was from room temperature to $1200^{\circ} \mathrm{C}$, and the weight of the specimen was $5 \mathrm{mg}$. Uniaxial compression tests of the specimens were carried out by WDW-100D universal testing machine with different strain rate of $1 \times 10^{-5}, 5 \times 10^{-5}, 1 \times 10^{-4}, 5 \times 10^{-4}$ and $1 \times 10^{-3} \mathrm{~s}^{-1}$, and different aspect ratio of 1:1, 1.5:1, 2:1, 2.5:1 and 3:1. The fracture surface and shear band were observed by Quanta Feg450 field emission scanning electron microscope(SEM).

\section{Result and discussion}

\subsection{Analysis of X-ray diffraction}

Figure 1 illustrates the XRD diffraction pattern of $\mathrm{Zr}_{61.88}$ $\mathrm{Cu}_{18} \mathrm{Ni}_{10.12} \mathrm{Al}_{10}$ alloy. It can be seen that the XRD pattern consists of one broad diffuse peak between diffraction angles $30^{\circ}$ and $45^{\circ}$, and no significant diffraction peaks corresponding to a crystalline phase showing that the specimen has complete amorphous structure.

\subsection{Analysis of DSC}

In order to characterize the thermodynamic stability of the metallic glass, the specimens were analyzed by DSC, displayed in figure 2. The specific thermodynamic characteristic parameters are reflected in Tab.1, where $T_{\mathrm{g}}$ is glass transition temperature, $T_{x}$ is crystallization start temperature, $T_{\mathrm{m}}$ is melting temperature and $T_{1}$ is liquidus temperature. It can be found that the supercooled liquid region $\Delta T_{\mathrm{x}}\left(\Delta T_{\mathrm{x}}=T_{\mathrm{x}}-T_{\mathrm{g}}\right)$ of the specimen is $85 \mathrm{~K}$, the reduced glass transition temperature $T_{\mathrm{rg}}\left(T_{\mathrm{rg}}=T_{\mathrm{g}} / T_{\mathrm{l}}\right.$ and the parameter $\gamma$ describing thermodynamic stability $\left(\gamma=T_{\mathrm{x}}\right)$ $\left(T_{\mathrm{g}}+T_{1}\right)$ are 0.568 and 0.409 respectively. The results exhibit that the specimen holds a wide supercooled liquid region, larger $T_{\mathrm{rg}}$ and parameter $\gamma$, which state that specimen possesses good thermodynamic stability.

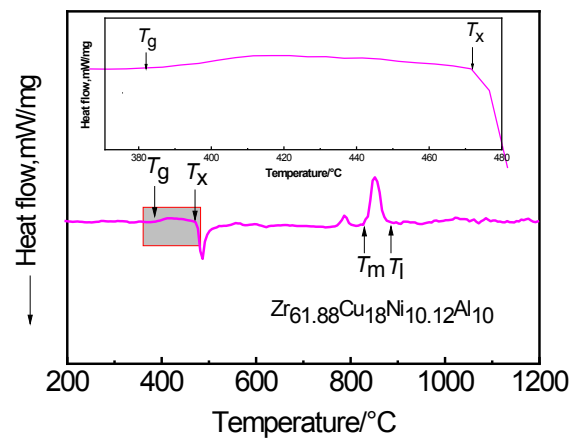

Figure 2 The DSC result of specimen
Figure 1 XRD pattern of specimen

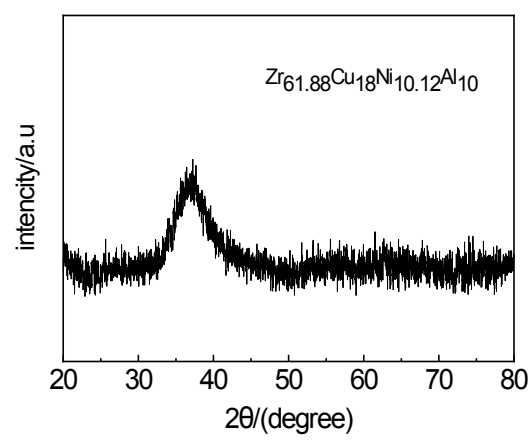

Table 1 The thermodynamic characteristic parameter of specimen

\begin{tabular}{ccccccc}
\hline$T_{\mathrm{g}} / \mathrm{K}$ & $T_{\mathrm{x}} / \mathrm{K}$ & $T_{\mathrm{m}} / \mathrm{K}$ & $T_{\mathrm{l}} / \mathrm{K}$ & $\Delta T_{\mathrm{x}} / \mathrm{K}$ & $T_{\mathrm{rg}}$ & $\gamma$ \\
\hline 659 & 744 & 899 & 1159 & 85 & 0.568 & 0.409 \\
\hline
\end{tabular}


3.3 Effect of strain rate on mechanical properties of $\mathrm{Zr}$ based metallic glasses

\subsubsection{Analysis of engineering stress-strain curve}

The compression tests of specimens with the aspect ratio of 2:1 was carried out by using a universal mechanical testing machine with different strain rate of $1 \times 10^{-5}, 5 \times 10^{-5}$, $1 \times 10^{-4}, 5 \times 10^{-4}$ and $1 \times 10^{-3} \mathrm{~s}^{-1}$. The engineering stress-strain curves of the specimens are shown in figure 3 and other mechanical properties are summarized in Tab.2. Combined with Table 2 and figure 3, it reveals that the yield strength of the specimen has slight changes with the change of compression strain rate, which indicates that the yield strength of the specimen is scarcely affected by the strain rate. However, the compressive strength and plastic strain of the specimen display the correlation of strain rate, which embodies that the compressive strength and plastic strain of the specimen decreases with the strain rate increasing. With the raise of strain rate, the plastic strain of specimens manifests a falling trend. The plastic strain decreases from $10.25 \%$ to $4.18 \%$. In addition, the compressive strength of the specimen reduces from $2002 \mathrm{MPa}$ to $1767 \mathrm{MPa}$ with the increase of strain rate. It can also be concluded that the elastic modulus of specimen fluctuates irregularly along with the change in strain rate while its variation range is small. At low strain rates, the plastic deformation of metallic glass can be more evenly distributed in each tiny volume unit of the glass, which is beneficial to the formation of multiple shear bands inside the metallic glass, and thus its plasticity is improved ${ }^{[22]}$.

From the local enlarged diagram of stress-strain curve(shown in figure 3 ), it can be seen that each curve has a certain sawtooth rheological behavior in the plastic deformation stage, and the sawtooth rheological behavior is very similar at the same order of strain rate, indicating that the strain rate is related to the sawtooth rheological behavior. Studies have shown that the sawtooth rheological behavior is generally obvious at low temperature and low strain rate, and with the increase of temperature and strain rate, the serration will gradually disappear or even completely disappear ${ }^{[23]}$. As shown in figure 3, at low strain rate, the sawtooth rheological behavior of sawtooth is mainly small sawtooth, and the stress change range of sawtooth is relatively uniform. With the increase of strain rate, the distribution of large and small sawtooth is mixed and the change range of stress is uneven. The smaller sawtooth is, the more interaction of shear bands in the plastic process is, that is, the stronger the plastic deformation ability is, and vice versa ${ }^{[24]}$. This is consistent with the results of this paper.

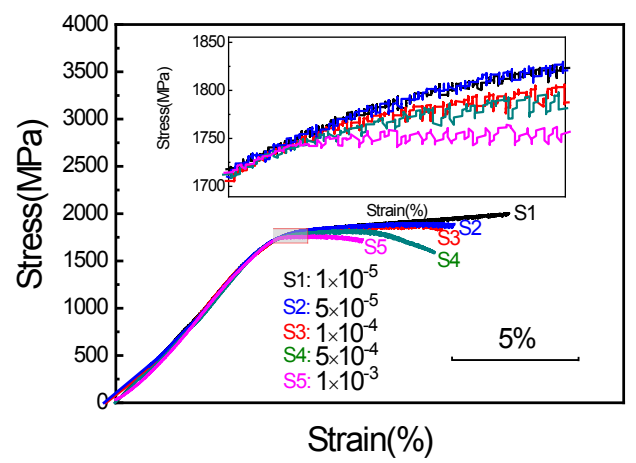

Figure 3 The compressive stress-strain curve of specimen with different strain rates at room temperature

Table 2 The mechanical performance parameter of specimen with different strain rates at room temperature

\begin{tabular}{|c|c|c|c|c|c|}
\hline $\begin{array}{l}\text { strain rate } \\
\qquad \varepsilon / \mathrm{s}^{-1}\end{array}$ & $\begin{array}{l}\text { elastic modulus E/ } \\
\mathrm{MPa}\end{array}$ & $\begin{array}{c}\text { plastic strain } \\
\varepsilon_{\mathrm{p}} / \% \\
\end{array}$ & $\begin{array}{c}\text { yield strength } \\
\sigma_{s} / \mathrm{MPa}\end{array}$ & $\begin{array}{c}\text { compressive strength } \\
\sigma_{\mathrm{bc}} / \mathrm{MPa}\end{array}$ & $\begin{array}{c}\text { fracture strength } \\
\sigma_{c} / \mathrm{MPa} \\
\end{array}$ \\
\hline $1 \times 10^{-5}$ & 29884 & 10.25 & 1457 & 2002 & 1999 \\
\hline $5 \times 10^{-5}$ & 32003 & 8.41 & 1470 & 1900 & 1888 \\
\hline $1 \times 10^{-4}$ & 29762 & 8.12 & 1306 & 1888 & 1869 \\
\hline $5 \times 10^{-4}$ & 30344 & 7.28 & 1538 & 1827 & 1557 \\
\hline $1 \times 10^{-3}$ & 31552 & 4.18 & 1597 & 1767 & 1727 \\
\hline
\end{tabular}

\subsubsection{Analysis of fracture morphology}

The fracture morphology of the specimens under different strain rates were shown in figure 4 . From figure 4(a-e), it can be found that the fracture morphology of the specimens is composed of continuous vein patterns, which is a typical fracture morphology after fracture of metallic glasses. With the increase of strain rate, the size of vein patterns in the fracture morphology of specimens enlarges gradually, showing the characteristics of uneven distribution. The regularity of vein patterns size from small to large in the fracture morphology of specimen in figure 4(a-e) also confirms the change of plastic strain from large to small in figure 3. Therefore, the rule can be summarized that the fine and uniform distribution of vein patterns correspond to larger plastic strain and higher strength, and the thick and uneven distribution of vein patterns reflects the smaller plastic deformation and lower strength of specimens ${ }^{[25]}$.

3.3.3 Analysis of surface shear band morphology

The formation and expansion of shear band is the main way of plastic deformation of bulk metallic glass at room temperature, so that the movement of shear band and the number of shear band in metallic glass will directly affect the plastic deformation mode and plastic strain of metallic glass. Based on the fact that the limited plastic strain of metallic glasses at room temperature is prone to be brittle fracture, it has become a challenge of how to improve the plasticity of metallic glasses at room temperature. Some researchers were keen to improve the plasticity of metallic 
glasses by adjusting the composition or by controlling the evolution of shear bands of metallic glasses during deformation ${ }^{[26,27]}$.

A variety of shear bands observed on the side surface of the specimen after fracture are exhibited in figure 5 . It is well known that the limited plastic strain of metallic glasses benefits from the generation and proliferation of shear bands and the interaction between shear bands during fracture ${ }^{[28]}$, such as figure 5(a), the lateral surface of the specimen is similar to the mountain shape and the morphology of the laminated shear band is extremely similar to that of the surface formed after the mountain fracture. It is a precise result because of the existence of multiple shear bands that the energy generated by stress in the fracture process of specimens can be released, thus enhancing the plastic strain of metallic glasses and inhibiting the occurrence of brittle fracture. On the other hand, the interaction between shear bands can promote the proliferation of shear bands, so that the energy generated by stress can be dispersed into multiple shear bands for release, thus effectively avoiding brittle fracture of specimens.
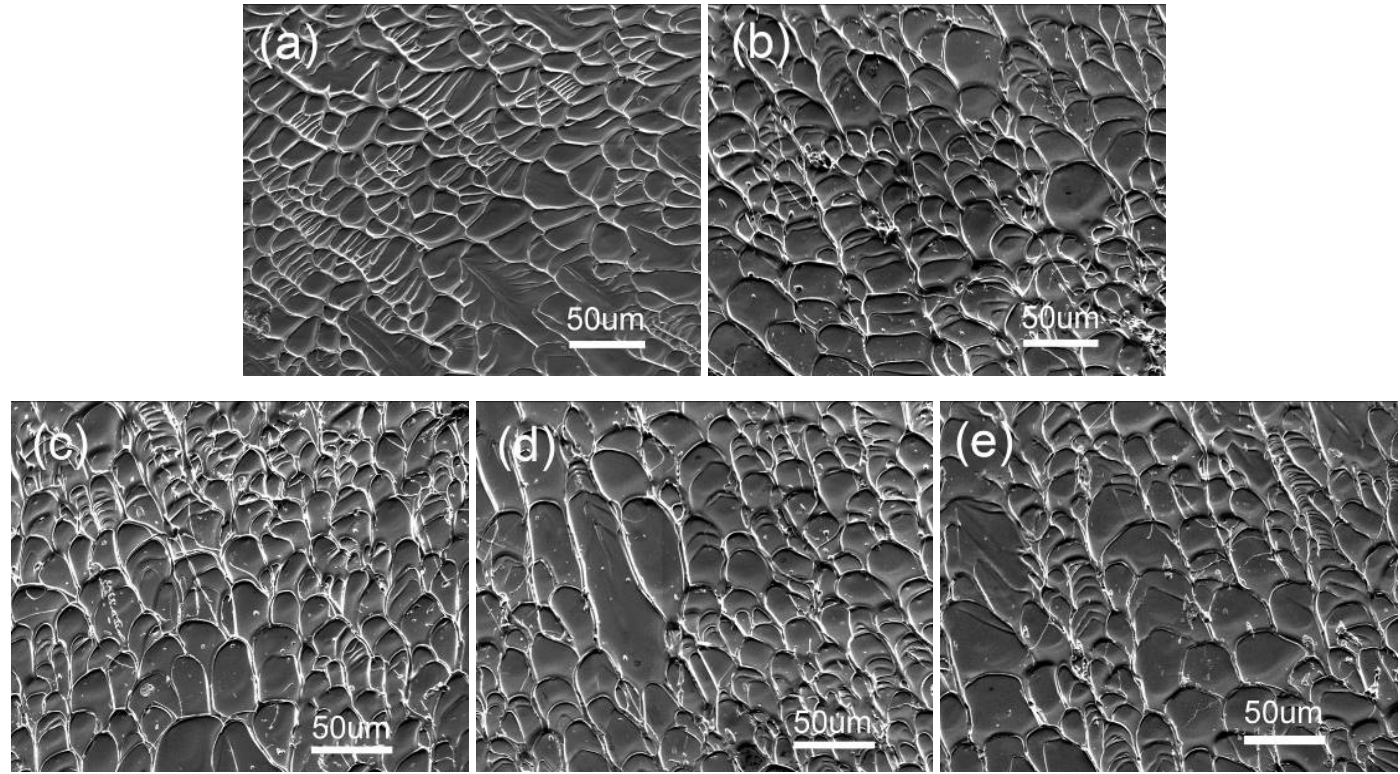

Figure 4 The compression fracture morphology of specimen with different strain rates at room temperature

(a) $1 \times 10^{-5} \mathrm{~s}^{-1}$, (b) $5 \times 10^{-5} \mathrm{~s}^{-1},(\mathrm{c}) 1 \times 10^{-4} \mathrm{~s}^{-1},(\mathrm{~d}) 5 \times 10^{-4} \mathrm{~s}^{-1},(\mathrm{e}) 1 \times 10^{-3} \mathrm{~s}^{-1}$
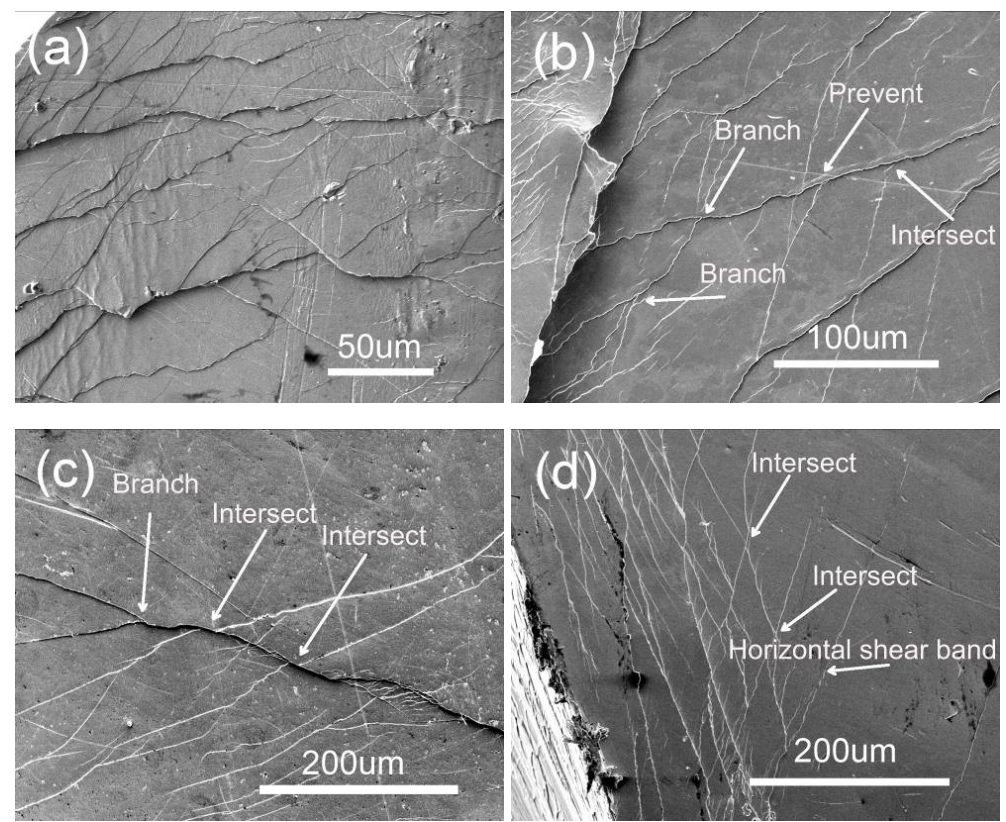

Figure 5 The shear band morphology of specimen under different strain rate.

(a) $1 \times 10^{-5} \mathrm{~s}^{-1}$, (b) $5 \times 10^{-5} \mathrm{~s}^{-1}$, (c) $1 \times 10^{-4} \mathrm{~s}^{-1}$ and (d) $5 \times 10^{-4} \mathrm{~s}^{-1}$ 
The morphology of the shear band under different strain rate were illustrated in figure 5. Obviously, there are three main forms of interaction between shear bands of metallic glasses, such as branch, prevent and intersect. It can be seen from figure 5(d) that the morphology of the shear band is mainly distributed in the direction parallel to the section. In addition, the horizontal shear band ${ }^{[29]}$ perpendicular to the direction of applied load is also observed from figure 5 , which is bound to interact with the main shear band with the loading direction of $45^{\circ}$. These interactions will inevitably promote the proliferation of shear bands and the expansion of shear bands in other directions, thus improving the plastic strain of metallic glasses ${ }^{[30]}$. Therefore, the appearance of horizontal shear band can promote the proliferation of shear band and further inhibit the brittle fracture of metallic glass to a certain extent. Furthermore, it can also be found that the shear bands, containing large number and more interaction between the shear bands, are observed on the surface of the specimens with the lower strain rate, that consistent with the specimen of it is presented as well plasticity. The sawtooth rheological behavior is caused by the extension of shear band, that is, the extension of shear band is discontinuous, and the reactivation of shear band will lead to serrated rheological phenomenon ${ }^{[31]}$. At low strain rate, sawtooth with smaller size and uniform stress corresponds to the more shear band of the compressed specimens. This can also be explained that the shear band of metallic glass can be uniformly expanded and proliferated at low strain rate, thus improving the strength and plasticity of metallic glass. At high strain rate, the shear of the specimen is not enough to propagate and proliferate, and the crack propagates along a single shear band, which leads to fracture. In summary, the compressive strain rate at room temperature and shear bands on the surface of the specimen (the number, the distribution intensity and the extent of the interaction between them) are negatively correlated.

3.4 Effect of aspect ratio on mechanical properties of $\mathrm{Zr}$ based metallic glass

\subsubsection{Analysis of stress-strain curve in engineering}

In addition to strain rate, aspect ratio is also one of the main factors affecting compression deformation of metallic glasses. In this experiment, the specimens with various aspect ratios of $1: 1,1.5: 1,2: 1,2.5: 1$ and $3: 1$ were subjected to Uniaxial compression tests at room temperature. The engineering stress-engineering strain curves of the specimens are illustrated in figure 6 . The specific mechanical properties parameters are obtained, as displayed in Tab.3. Combined with figure 6 and table 3, it can be clearly seen that the sawtooth flow occurs in the specimens during compression, and the plastic strain decreases with the increase of aspect ratio. The yield strength of the specimen changes as aspect ratio increases, which tends to decrease at first and then increase, but the range of variation is very slight. The specimen has a maximum plastic strain of up to $25.42 \%$ when the aspect ratio is $1: 1$. In addition to large plasticity, the specimen also manifest obvious workhardening phenomenon, and its strength is also obviously higher than that of the specimens with other aspect ratio. The smallest plastic strain occurs when the aspect ratio is $3: 1$, and the plastic strain is only $1.97 \%$.

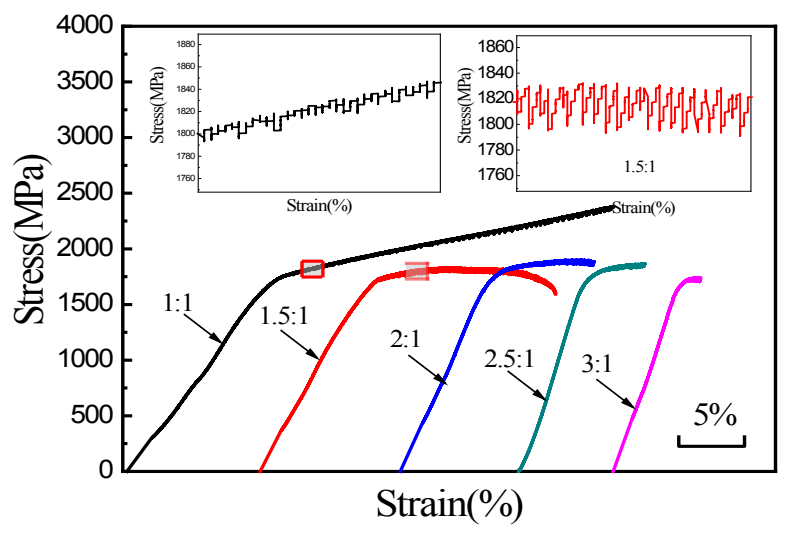

Figure 6 The compressive stress-strain curve of specimen with different aspect ratio at room temperature

Table 3 The mechanical performance parameter of specimen with different aspect ratio at room temperature

\begin{tabular}{cccccc}
\hline $\begin{array}{c}\text { aspect } \\
\text { ratios }\end{array}$ & $\begin{array}{c}\text { elastic modulus E/ } \\
\mathrm{MPa}\end{array}$ & $\begin{array}{c}\text { plastic strain } \\
\varepsilon_{\mathrm{p}} / \%\end{array}$ & $\begin{array}{c}\text { yield strength } \\
\sigma_{\mathrm{s}} / \mathrm{MPa}\end{array}$ & $\begin{array}{c}\text { compressive strength } \\
\sigma_{\mathrm{bc}} / \mathrm{MPa}\end{array}$ & $\begin{array}{c}\text { fracture strength } \\
\sigma_{\mathrm{c}} / \mathrm{MPa}\end{array}$ \\
\hline $1: 1$ & 19280 & 25.42 & 1436 & 2381 & 2375 \\
$1.5: 1$ & 19852 & 15.19 & 1394 & 1832 & 1593 \\
$2: 1$ & 31001 & 7.73 & 1371 & 1900 & 1853 \\
$2.5: 1$ & 43503 & 4.78 & 1380 & 1866 & 1842 \\
$3: 1$ & 41440 & 1.97 & 1582 & 1741 & 1707 \\
\hline
\end{tabular}

According to the influence of sample size and aspect ratio on the plasticity of amorphous alloy, Han ${ }^{[32]}$ proposed a parameter called shear band instability index. According to Han's analysis, the specimens with small aspect ratio have larger critical shear band instability parameter Scr, therefore, the specimens have better plasticity. From the local enlarged diagram (shown in figure 6) of local stress- strain curve, it can be seen that some curves show different sawtooth rheological behavior in the plastic deformation stage. Especially when the ratio of height to diameter is 1:1, the plasticity of the specimen with uniform stress range and small serration is significantly greater than that of the specimen with large aspect ratio.

The relationship among elastic modulus, strength, 
plastic strain and aspect ratio of specimens is drawn by analyzing the compression mechanical properties parameters in Tab.3. The results are displayed in in figure 7 (P represents the aspect ratio of specimens). From figure 7 (a), when $\mathrm{P}$ varies from 1 to 2.5 , the elastic modulus of the specimen raises with the increase of aspect ratio. Especially, the elastic modulus rockets sharply with the increase of aspect ratio from 1.5 to 2.5 , and decreases when $\mathrm{P}$ changes from 2.5 to 3 . In addition, the plastic strain of the specimen decreases with the increase of aspect ratio. Figure 7(b)

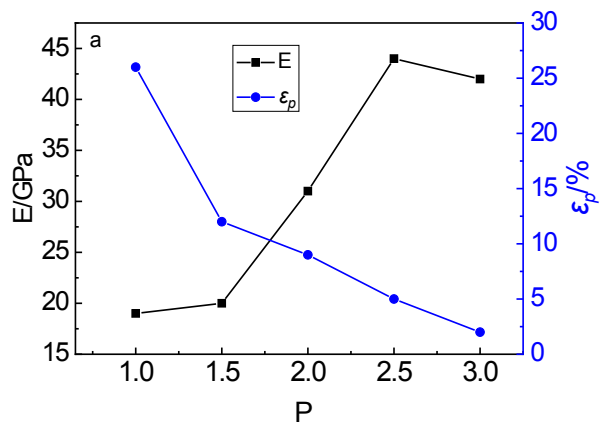

reveals the relationship between the compressive strength, fracture strength and aspect ratio of the specimen. It can be easily found that the compressive strength and fracture strength of the specimen reach the maximum when $\mathrm{P}$ is 1 . Increasing $\mathrm{P}$ to 1.5 , the strength of the specimen plummets sharply to a minimum. When $\mathrm{P}$ increases from 1.5 to 2 , the strength of the specimen grows. Persistently increasing $\mathrm{P}$ to greater than 2 , the strength of the specimen decreases gradually.

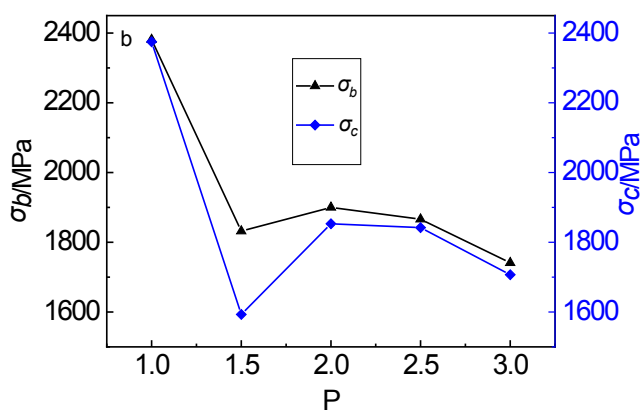

Figure 7 The relationship between elastic modulus, strength, plastic strain and aspect ratio of specimen.

\subsubsection{Analysis of fracture morphology}

It can be found from figure 8 that the fracture morphology of the specimens after compression fracture is composed of typical vein patterns. Figure $8(a, b, c, d)$ in turn represents the fracture morphology with an aspect ratio of $1.5: 1$, $2: 1,2.5: 1$ and $3: 1$. The specimen with the aspect ratio of 1:1 didn't break after compression, therefore, the fracture morphology of specimens was not observed. From figure $8(\mathrm{a})$, the fracture morphology of specimens is composed of fine vein patterns, and the size is relatively small, which conforms to the rule that the finer vein patterns of metallic glass correspond to the higher strength and plasticity ${ }^{[25]}$. In addition, the size of the specimen vein patterns increases with the increase of aspect ratio, and indicates the characteristics of uneven distribution of the grain. When the aspect ratio is $3: 1$, the fracture morphology of the specimen appears with the vein patterns of large size and discontinuity distribution, which may be one of the causes for the poor plasticity at room temperature. Compared with figure $8(\mathrm{a}-\mathrm{d})$ and figure $4(\mathrm{a}-\mathrm{e})$, we can find that there is a negative correlation between the size of vein patterns in the fracture morphology of specimens and the plastic strain of specimens. As a result, the size of vein patterns is also one of the gist for explaining the plastic strain of metallic glasses ${ }^{[25]}$.
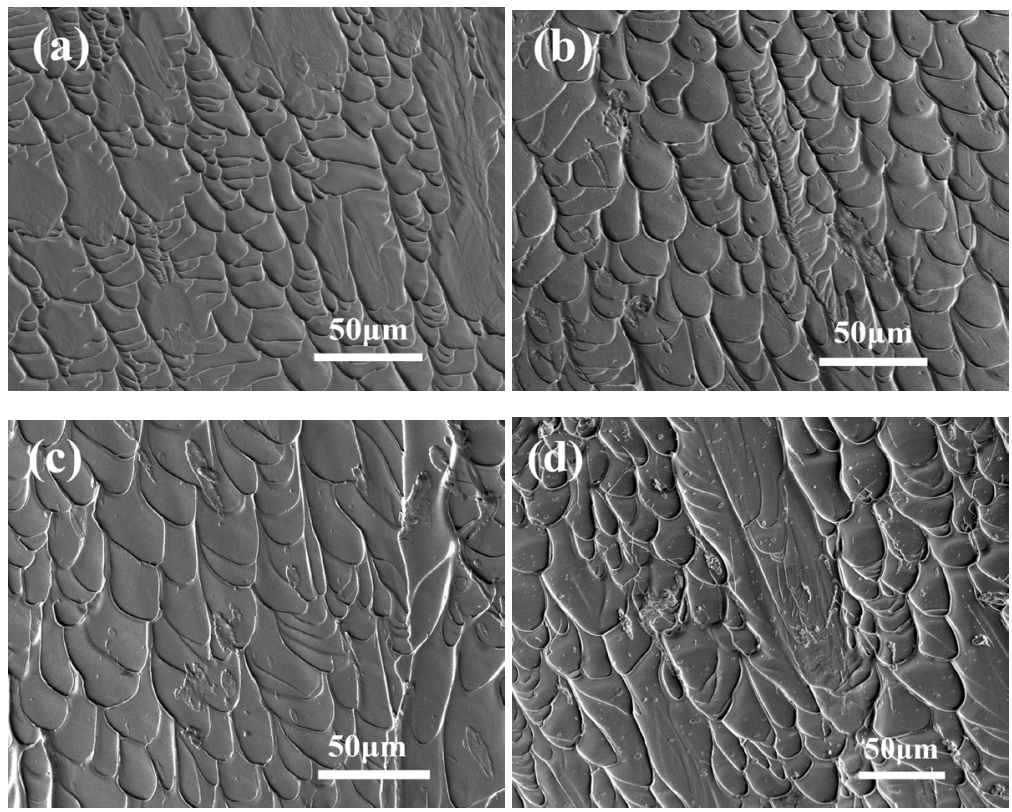

Figure 8 The compression fracture morphology of specimen with different aspect ratio at room temperature.

(a) $1.5: 1 ;$ (b)2:1; (c) $2.5: 1 ;$ (d) $3: 1$ 


\section{Conclusions}

(1) The plastic deformation at room temperature of the specimen is sensitive to the strain rate. When the strain rate is $1 \times 10^{-5} \mathrm{~s}^{-1}$, the specimen holds excellent mechanical properties, due to the shear bands with large number and dense distribution produced at lower strain rate can be uniformly extended and diffused. An increase in strain rate decreases the fracture strength, plastic strain and compressive strength of specimen.

(2) The compression plasticity of specimens at room temperature is closely related to the aspect ratio of compression specimens, which is mainly manifested by the deterioration of the compressive mechanical properties at room temperature with the increase of aspect ratio. Furthermore, specimen containing the aspect ratio of 1:1 possesses well excellent mechanical properties, among which the plastic strain is $25.42 \%$, the compressive strength is $2381 \mathrm{MPa}$, and the fracture strength is $2375 \mathrm{MPa}$.

Conflict of Interest: The author(s) declare(s) that there is no conflict of interest regarding the publication of this paper.

Acknowledgments: This work was supported by the National Natural Science Foundation of China (Grant No.51661016, No. 51861021, No. 51571105), Wenzhou Public Welfare Science and Technology Project (G20170019) and The Natural Science Foundation of Gansu Province (Grant No.145RJZA090); Hongliu Firstclass Discipline Construction Plan of Lanzhou University of Technology.

\section{References}

[1] Li N, Xu X, Zheng Z, et al. Enhanced formability of a Zrbased bulk metallic glass in a supercooled liquid state by vibrational loading[J]. Acta Materialia, 2014, 65:400-411.

[2] Deng L, Yao D, Zhou P, et al. Influence of size-dependent free volume variation and distribution on the thermoplastic flow behavior of Zr-based bulk metallic glass[J]. Journal of Alloys and Compounds, 2019, 783:272-278.

[3] Ping Z, Zhong M, Long Z, et al. Universal percolation threshold for ductile-brittle transition of amorphous alloys[J]. Journal of Non-Crystalline Solids, 2018, 488:1418.

[4] Jafary-Zadeh M, Tavakoli R, Koh J J, et al. Effect of chemical composition and affinity on the short- and mediumrange order structures and mechanical properties of $\mathrm{Zr}$ $\mathrm{Ni}$-Al metallic glass[J]. Journal of Non-Crystalline Solids, 2017,456:68-75.

[5] Bibhu P.S., Amlan D, Rahul M. Mechanism of negative strain rate sensitivity in metallic glass film[J]. Journal of Alloys and Compounds,2019,784:488-499.

[6] Hasani S, Rezaei-Shahreza P, Seifoddini A, et al. Enhanced glass forming ability, mechanical, and magnetic properties of $\mathrm{Fe}_{41} \mathrm{Co}_{7} \mathrm{Cr}_{15} \mathrm{Mo}_{14} \mathrm{Y}_{2} \mathrm{C}_{15} \mathrm{~B}_{6}$, bulk metallic glass with minor addition of $\mathrm{Cu}[\mathrm{J}]$. Journal of Non-Crystalline
Solids, 2018,497:40-47.

[7] Bordeenithikasem P, Shen Y, Tsai H L, et al. Enhanced mechanical properties of additively manufactured bulk metallic glasses produced through laser foil printing from continuous sheet metal feedstock[J]. Additive Manufacturing, 2018, 19:95-103.

[8] Meduri C, Hasan M, Adam S, et al. Effect of temperature on shear bands and bending plasticity of metallic glasses[J]. Journal of Alloys and Compounds, 2018, 732:922-927.

[9] Zhang H Y, Zheng G P. Simulation of shear banding in bulk metallic glass composites containing dendrite phases[J]. Journal of Alloys and Compounds, 2014, 586:262-266.

[10] Zhang S G, Hu J, Zhu XX et al. High strain rate compression deformation behavior of Zr-based amorphous alloy in the supercooled liquid region[J]. Chinese Journal of Nonferrous Metals, 2005, 15(8):1219-1224

[11] Chen D M, Wang G, Sun J G et al. Deformation behavior of tungsten wire reinforced zirconium-based bulk amorphous alloy composites at high strain rate[J]. Journal of metals,2006, 42(9):1003-1008

[12] Lewandowski J J, Lowhaphandu P. Effects of hydrostaticpressure on the flow and fracture of abulk amorphous metal [J]. Philos Mag A, 2002, 82(17 - 18) :3427 - 3441.

[13] Yuan B. The study of the serrated flow behavior in $\mathrm{Zr}$ based bulk metallic glasses at room temperature[D]. Taiyuan University of Technology, 2018.

[14] Wei R, Chang Y, Yang S, et al. Strain Rate Sensitivity Variation in Cu-Zr-based Bulk Metallic Glass Composites Containing B2-CuZr Phase[J]. Rare Metal Materials and Engineering, 2016, 45(3):542-547.

[15] Tomasz K, Krzysztof P, Grzegorz C, et al. Effect of strain rate and crystalline inclusions on mechanical properties of bulk glassy and partially crystallized Zr52.5Cu17.9Ni14.6Al10Ti5 alloy [J]. Transactions of Nonferrous Metals Society of China, 2019, 1036-1045.

[16] Huang J S, Liu Y, Chen S Q, et al. Progress and application of Zr-based amorphous alloys[J]. The Chinese Journal of Nonferrous Metals. 2019,29:1036-1045.

[17] Tariq N H, Akhter J I, Khalid A, et al. Effect of prior compression treatment on the deformation behavior of $\mathrm{Zr}$ based bulk metallic glass[J]. Materials Chemistry and Physics, 2014, 143(3):1384-1390.

[18] Mihailov L, Spassov T, Bojinov M. Effect of microstructure on the electrocatalytic activity for hydrogen evolution of amorphous and nanocrystalline $\mathrm{Zr}-\mathrm{Ni}$ alloys[J]. International Journal of Hydrogen Energy, 2012, 37(14).

[19] Zhou M, Huang X, Hagos K, et al. Nanoporous copper fabricated from $\mathrm{Zr} 65 \mathrm{Cu} 17.5$ Fe 10 Al 7.5, amorphous alloy and its electrocatalytic oxidation performance[J]. Intermetallics, 2017, 90:23-29.

[20] Khan M. M, Deen K. M, Haider W. Combinatorial development and assessment of a $\mathrm{Zr}$-based metallic 
glass for prospective biomedical applications[J]. Journal of Non-Crystalline Solids, 2019, 523: 119544.

[21] Hong X, Tan Y, Zhou C, et al. Microstructure and tribological properties of Zr-based amorphous-nanocrystalline coatings deposited on the surface of titanium alloys by Electrospark Deposition[J]. Applied Surface Science, 2015, 356:1244-1251.

[22] Jiang W H, Fan G J, Choo H, et al. Ductility of a Zr-based bulk-metallic glass with different specimen geometries[J]. Materials Letters, 2006, 60(29-30):3537-3540.

[23] Christopher A S, Alan C L, Nieh T G. New regime of homogeneous flow in the deformation map of metallic glasses: elevated temperature nanoindentation experiments and mechanistic modeling[J]. Acta Materialia, 2004, 52(20):5879-5891.

[24] Qu B. The Study of the Serrated Flow Behavior in Zrbased Bulk Metallic Glasses at Room Temperature [D]. Taiyuan University of Technology, 2018.

[25] Sun M, Liu L. Wang J F, et al. Effect of Nb addition on thermal stability, glass forming ability and mech anical properties of Zr- based bulk amorphous alloys (in Chinese). Acta Metall Sin, 2005, 41(5):534 -538

[26] Farnaz A, Davani S H, Harald R, David G, Annett G, Gerhard W. On the shear-affected zone of shear bands in bulk metallic glasses[J]. Journal of Alloys and Compounds,2020,837.

[27] Han Z H, Feng Y Y, Li F. Minor Nb Addition Induced Microstructure Evolution and Multiplication of Shear Bands in Cu-Zr-Ti Based Bulk Metallic Glasses[J]. Hot Working Technology, 2019, 048(008):84-87.

[28] Yedla N, Ghosh S. Nature of atomic trajectories and convective flow during plastic deformation of amorphous Cu50Zr50 alloy at room temperature-classical molecular dynamics studies[J]. Intermetallics, 2017, 80:40-47.

[29] Inoue A, Zhang W, Tsurui T, et al. Unusual roomtemperature compressive plasticity in nanocrystaltoughened bulk copper-zirconium glass[J]. Philosophical Magazine Letters, 2005, 85(5):221-237.

[30] Wang X D, Qu R T, Wu S J, et al. Improving fatigue property of metallic glass by tailoring the microstructure to suppress shear band formation[J]. 2019,7(100407).

[31] Hufnagel T.C, El-Deiry P, Vinci R P. Development of shear band structure during deformation of a Zr57Ti5Cu20Ni8Al10 bulk metallic glass[J]. Scripta Materialia, 2000, 43(12):1071-1075.

[32] Han Z H, Wu W F, Li Y, et al. An instability index of shear band for plasticity in metallic glasses [J]. Acta Mater, 2009, 57(5): 1367-1372 